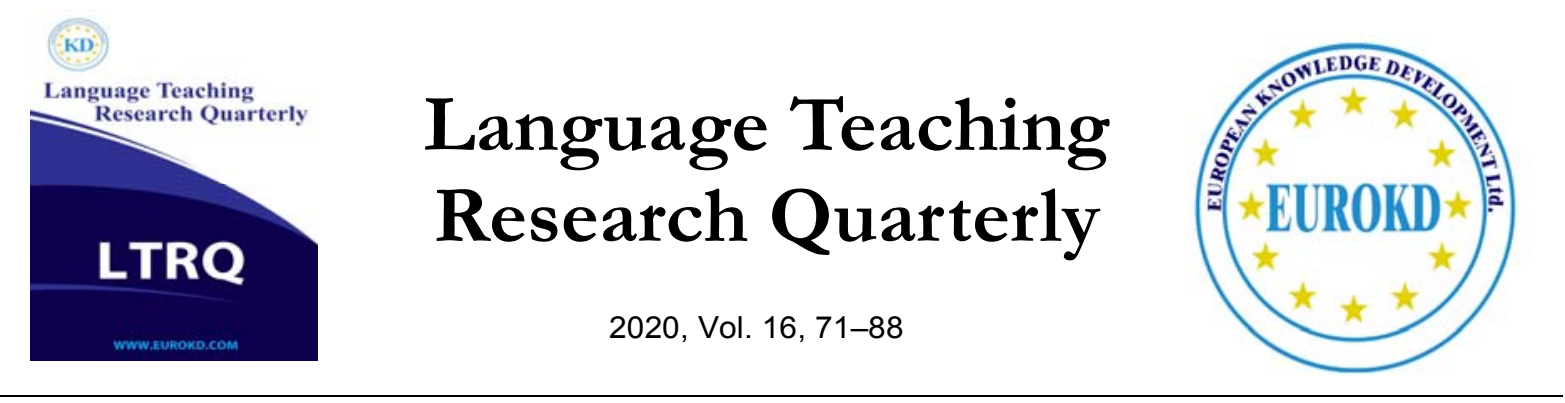

\title{
Questioning the Policy of Teaching 'Moral Education' through English as a Foreign Language in a Private School in Dubai
}

\author{
Nesrin Tantawy \\ Graduate School of Education \\ University of Exeter, Exeter, UK
}

Received 02 February 2020

Accepted 10 April 2020

\begin{abstract}
Moral Education (ME) is meant to turn all young individuals into morally autonomous adults by providing them with the required competence to judge for themselves what is morally right. To align with such holistic concepts, the UAE Government has launched ME as a school subject to promote tolerance and introduce universal values that are in accordance with the UAE vision. Many schools where students' population consists mainly of Arabs have decided to adopt English as the medium of instruction (EMI) in teaching ME even though adopting Arabic as the language of instruction was an option at their disposal. Hence, this study is meant to question employing the EMI policy in teaching ME to Arab students in a private school in Dubai. Since teachers are one of the main stakeholders in the teaching-learning process, their perceptions of the target policy and its impact on students' understanding of the ME syllabus were investigated through ten semi-structured interviews. A second set of qualitative interviews was administered with three of the senior management personnel at the same school to examine the issue through different binoculars. Results show that most teachers disapprove of the adopted policy; moreover, teachers' voice was never taken into consideration by the school administration.
\end{abstract}

Keywords: Moral Education, English as a Medium of Instruction (EMI), Teachers’ Voice.

\section{Introduction}

Morality is defined by Bramble and Garrod (1977) as "perspective on life - a set of principles which, applied to given circumstances help to guide one's actions" (p. 105). They also assert the 
same viewpoint as they identify morality as pertaining to habits, customs and ways of life and the classification of each as being right or wrong. They go on to introduce the concept of a moral principle of which they present three views: actions for which we can be held accountable, principles which are favoured over others, and values that are commonly accepted. Hall (1979) interprets moral education (ME) as "the business of helping students learn to make better decisions and in particular to make decisions which reflect knowledge and consideration of the importance of moral values" (p. 17). In some contexts, the term 'character education' is used instead as ME has had a religious reference that caused some to feel uncomfortable. The word 'character' that stresses establishing good habits and eliminating inadequate ones has struck a popular balance. Yıldırım (as cited in Demirel, Özmat \& Elgün, 2016) describes character as bringing positive qualities to a person's thoughts, feelings and behaviours while taking shape from the childhood affected by one's family, friends and school.

\section{Literature Review}

Since culture is seen as normative for individuals, they tend to internalize the human culture through education, and thus education is considered moral in its essence. By assimilating culture, individuals do not just obtain knowledge, they also learn a way to act which is the genuine goal of ME. Good individuals who act for the common good form the basis for a good society (Bayer, 2017). The interaction between ethics, values, and norms leads to what is called 'morality'. In the light of the fact that people of a society often face situations in which they are morally tested, morality can be defined not only as the set of beliefs and ethics but also as the implementation of such values in a society. From a wider perspective, a society's shared moral perception reflects the moral perception of each individual; consequently, morality influences the decision-making process in individuals'daily experiences while ME helps create a morally balanced society (Durmuş, 2019).A distinction between what is called narrow and broad morality should be made in this regard. According to van der Kooij, de Ruyter, and Miedema (2015), narrow morality is defined as the primary rules and values that enable individuals within the same society to communicate or the so-called 'other-regarding' virtues. Broad morality, on the other hand, is as 'self-regarding' as it is 'other-regarding' since it "contains the body of ideals, principles and values that determine a person's acts designed to realise his or her most important aim and give meaning to life" (p. 348).

Moral education is concerned with the "moral awareness of the rightness of what is good and the wrongness of what is evil...[a] morally-aware person is one who cares both about thinking and behaving - not one who shuts off moral awareness when convenient, nor one who treats moral dilemmas primarily as playing verbal academic games" (Watson, 2018, p. 169). ME can also be referred to as "the education of students' ideological, political, moral, legal and psychological health" (Qin, 2018, p. 460). In the educational arena, ME curriculum is a vital means through which schools present and enhance rules, strategies, values, measures, and activities (Krek, Hodnik \& Vogrinc, 2019); therefore, ME should legitimately foster "some desirable set of values, sensitivities and character dispositions" (Aloni, 2020, p. 98). 
The objectives of ME are mainly to systematically teach students how to be proactive through making autonomous moral judgements, how to think critically and reflectively, and how to solve real-life moral problems. Put differently, ME is the impartment of knowledge, values, and attitudes that help learners become informed, responsible citizens. ME as a school subject stresses active learning on the part of the students through participating in collaborative learning activities and classroom discussions. Teachers are expected to help students gain a profound understanding of virtues in order for learners to be able to imitate and apply such values to reallife contexts (Nishino, 2017). In this context, schools and teachers are seen by 'The Character Education Manifesto' as the main agents of introducing and promoting ME and that schools are compelled to promote personal and communal values among which are courage, responsibility, conscientiousness, service, and respect. Lately, teachers have been considered as more than an information bank and they have been urged to take on a transformative role where they play a guiding role in the life of the learners. Many believe that teachers and schools should help children become ethically mature learners who are capable of moral thought and action upon facing moral issues (Shaaban, 2005).

\section{School Role}

Students' moral development has always been recognized as one of the main objectives of schooling.Parents see schools as being largely responsible for the moral behaviour of their children. In literature, the moral awareness of children is well shaped when parents and teachers keep open communication channels so that they can work in collaboration to change any behavioural disorders; children need to see role models of good character in a variety of situations within the family and community at large, not to mention the school community (van der Kooij,2015).The emergence of concerns about immoral behavior such as, violence in schools, bullying, and cheating has given rise to the need for "moral inquiry skills and knowledge, which can best be taught through formal schooling" (Bleazby, 2020, p. 84).

It has also been stressed that teachers are capable of nurturing students' moral inquiry skills through age-appropriate classroom activities during which teachers model and give instructions as a means of scaffolding students. A comprehensive awareness of various moral issues and advanced moral inquiry skills is best offered through moral education curriculum delivered by formal educational institutions. Moral education aims at fostering learners' sense of responsibility, confidence, ability to communicate with others, and reflective and critical thinking skills (Durmuş, 2019). Schools are responsible for transmitting such values and skills through implementing ME curriculum. In the same vein, teachers' actions are seen to have a paramount impact on students' moral decisions which elects teachers to be role models. Bodies of research about ME show that a school positive atmosphere influences learners' character. In this respect, everyone in the school should take partnership in conducting the $\mathrm{ME}$ curriculum.Hence, schools are required to create a positive, moral environment that would stimulate students' good behaviors (Demirel, Özmat \& Elgün, 2016). As stated by Meindl, 
Quirk, and Graham (2018), the most effective practices for developing students' morality can be attributed to strong relationships and school community.

A wide range of outcomes has been demonstrated by effective moral education. It has been evident that ME associates with academic motivation and attainment, prosocial values, commitment to learning, moral-reasoning skills, responsibility, self-efficacy, self-control, selfesteem, and respect for teachers. Furthermore, effective ME has been effectual in reducing absenteeism, discipline issues, academic failure, drop out concerns, and school anxiety(Berkowitz \& Bier, 2004; Was, Woltz \& Drew, 2006). As a result, such outcomes should serve as guidelines to schools for implementing their ME programmes. What each individual school must decide on, however, is the approach that best suits its young learners and its society. According to KHDA school supplement (2017-2018), while the ME course is not graded or subject to examinations, UAE Moral Education programme can unite all its schools by setting clear expectations for students' behavioural and affective domains.

\section{Teachers' Voice}

In any organization, the decision-making process should not be executed only by employers; employees' contribution should also be sought for being an indispensable source of information on potential organizational matters. Employee voice is defined in literature as the ability of a working member to voice their opinions and suggestions on work-related issues, including injustice and mismanagement, with the intent of improving organizational functioning. For educational institutions, voice assumes a sense of teachers' autonomy that denotes a democratic organizational culture. Having said that, it is a firmly established notion that teacher voice should be an important component of any school initiative and an organizationally desired behaviour; teacher voice is considered key to a school sustainability. According to literature that emphasizes the fundamentality of teacher voice, "the preliminary motive for voice is assumed to improve the performance of organizations or to provide collective benefits"(BAS \& TABANCALI, 2020, p. 187).

However, the importance of teacher voice has largely been ignored as a source of information and a means of empowerment; this prevents both researchers and practitioners from understanding the complexities of the teachers' daily life and how classroom activities unfold. The lack of proper voice systems, defined by Wilkinson, Gollan, Kalfa, and Xu (2018) as a "set up within an organisation to shape and channel participation" (p. 712), would have a detrimental impact on teachers' motivation, job satisfaction, and on the organizational performance in general (Tantawy, 2020). It is further asserted that teachers as employees tend to not voice their opinions in the workplace, referred to as 'silence of employees' by BAS and TABANCALI (2020) and Wilkinson et al. (2018), due to many factors among which are inefficacy of the organizational voice system, lack of motivation, and fear of consequences.

When their voice is restrained, teachers, like all oppressed groups, lose their voice (Alamri, 2019). As a result, the connections between the dominator model, authoritarian relationships, and the oppression of teacher voice should be looked into. It is also worth highlighting how teachers should be involved in any kind of policy making. Teacher voice is especially important in 
understanding school culture because teachers are contributors to and recipients of their schools'environment. However, it remains the case that teachers are not central players in establishing educational policies, nor are they necessarily able to shape professional practice in their own schools. Ellison, Anderson, Aronson, and Clausen (2018) stress the fact that teachers come last in the policy hierarchy and are always "represented through a pathologizing discourse of deficits, resistance to change, and an overall lack of authority to act in the public sphere" ( $p$. 158). Teachers are widely perceived as powerless, marginalized, 'non-elite policy actors' whose voice need to be raised in the educational policy debate.

Bas and Sentürk (2019)advocate the centrality of involving teachers in curriculum development; they emphasize that teachers are the experts on how the curriculum works in the classroom and thus should play a vital role in the curriculum evaluation process. The lack of teachers' contribution to the curriculum development process sometimes results in the inapplicability of the curriculum. For the curriculum development process to be fruitful, all parties including teachers, students, and parents as the most marginalized stakeholders should be involved. Teachers' classroom experiences and knowledge should be highly regarded as a major success factor of any educational reform. Bas and Sentürk (2019)go on to confirm that teachers should be given part in classroom research and curriculum designing; teachers should take part in curriculum-related committees which involve evaluating curriculum, making recommendations, collecting data, contacting parents, adapting teaching materials, doing research, and receiving feedback. Unfortunately, the language policy of all academic institutions is often foisted by a governing body of authority which imposes such policies on teachers rather than involving them. Teachers and learners, the two main stakeholders in this process, are equally influenced by such policies and practices, yet their opinions and attitudes are "rarely considered, and usually excluded from this vital decision" (Alenezi, 2010, p. 2).

\section{UAE Context: Policy and Aims}

The aim of ME as highlighted in Pring's (2019) review paper is that it should help all young individuals become morally autonomous adults by providing them with the competence to judge what is morally right. Secondly, ME should equip young people with the flexibility to adapt to new situations they might encounter in a rapidly changing world. In line with such concepts, the UAE Government, in 2016, launched Moral Education as a school subject to introduce universal values and principles that are valid across all communities. At its heart, the ME course aims to teach children to participate in life in a responsible, productive and engaged manner. It is less about instructing students on how to behave and more about enabling them to determine the right course of action on their own. As per the Knowledge and Human Development Authority's inspection supplement (2017-2018), moral education is a fundamental aspect of students' development on the personal and social level, and schools should provide guidance in this respect. The ME programme is built around four pillars: character and morality, the individual and the community, cultural studies, and civic studies. The yearly school inspection of ME administered by KHDA focuses on the following key components of provision: curriculum, 
teaching and the selection of teachers, pedagogical approaches and the use of ME programme textbooks, engagement of families, assessment, and reporting to parents.

\section{EMI and the Language Barrier}

Conforming to the fact that English plays a leading role in the global market, the UAE finds no choice other than preparing its workforce to function in the world economy through achieving a proper command of English; consequently, English has evolved from being a foreign or second language to the language of academic disciplines (Moore-Jones, 2015). A medium of instruction indicates the language through which teaching non-language, content subjects takes place (Macaro, 2018). In this context, English is considered as a tool rather than a subject.

The effectiveness of EMI in the UAE and the Arab world and how students can be more eligible to excel in academic subjects when they are taught through their mother tongue as the most familiar language to them is questioned in a number of studies (Troudi, 2009; Belhiah \& Elhami, 2015; Al-Issa, 2017; Wanphet \& Tantawy, 2018). Moreover, learning is believed to be a means by which students engage in learning activities, communicate, and interact in order to exchange knowledge. For sound learning, students should be well-acquainted with the language of instruction whereas EMI "presents academic and social challenges" in education as claimed by Alhamami (2015, p. 105).

A teacher assumes a distinctive role of assisting learners in constructing knowledge; students interact actively with the teacher as a mediator whose role is to scaffold students by bringing them closer to the content. More to the point, using the students' first language (L1) has consistently been acknowledged as a resourceful tool; the mother tongue for a learner is his "strongest ally and should, therefore, be used systematically" is a belief highlighted in Butzkamm's research (2003, p. 30). Dujmović (2014)brings forth the relationship between employing L1 and maintaining a humanistic teaching approach that tends to combine what learners think and feel with learning the target subject. Levine (2014) confirms that L1 is so pedagogically and socially functional that it should be guaranteed a natural place in the teachinglearning settings. Almoayidi (2018)expounds a powerful argument saying that implementing L1 in teaching plays a facilitating role that allows learners to work at higher cognitive levels. Adil (2019) argues that insisting on not using L1 in attempting linguistically and cognitively complex tasks means intentionally disregarding a pivotal cognitive tool.

In Moral Education classes, the tool of the greatest importance is language, the prominent joint activity is the interactional discourse, and the purpose of the activity is to create common knowledge and enhance understanding of profound concepts. Moral functioning is unavoidably mediated by language which takes place mainly as an "inner moral dialogue" that occurs necessarily in the learner's L1.Considering that language is the best social medium, processes of social communication and social relations give rise to moral functioning (Lewis, 2019, p. 43). Costa et al.'s (2014) experimental research offers potential evidence that using a foreign language would reduce functional resolutions of moral dilemmas. In addition, the added cognitive load and anxiety of using a foreign language could decrease the effective choice. In general, a foreign language elicits less intense emotional reactions relative to a native language. 
In this research, it has been hypothesized that moral judgments in a foreign language would be less affected by the emotional reactivity elicited by a dilemma. The results have shown that people's moral judgments and decisions depend on the native-ness of the language in which a dilemma is presented. These results are important because they show that identical dilemmas may elicit different moral judgements depending on a seemingly irrelevant aspect such as the native-ness of the language. Most likely, a foreign language reduces emotional reactivity. Another factor that may contribute to the effect of a foreign language on moral judgement is cognitive fluency. Studies have shown that using a foreign language reduces cognitive fluency and it might diminish the impact of intuitive processes on moral judgment.

\section{Rationale}

As a former schoolteacher, educator and a head of the department, I have witnessed some controversies regarding the ideal implementation of $\mathrm{ME}$ curriculum through the English language as the only medium of instruction. Since EMI is at the heart of the teaching-learning process in the target American school in Dubai, this research is meant to delve into the different perceptions of both teachers and administrators on using EMI to introduce and implement ME curriculum despite the fact that all schools across the UAE are given the liberty of choice to teach ME through the Arabic language. Consequently, the research questions of the current study are:

1- How do English language teachers perceive of the imposed policy of teaching Moral Education through the English language?

2- How do English teachers perceive of the impact of using English as the medium of instruction on students' level of understanding and class dynamics?

3- What is the school administration personnel's perspective on choosing English as the medium of instruction in teaching Moral Education?

\section{Research Design}

\section{Research Paradigm}

A research paradigm is a view that demonstrates assumptions about the nature of knowledge, epistemology, the nature of social reality, ontology, and about research methodology. By deciding on a specific research paradigm, a researcher expresses his/her stance in relation to the target phenomenon (Troudi, 2010). This study is critical in nature with the ontological stance based on "persons in society" and the epistemological stance based on social constructivism or understanding the world through social interests (Higgs, Titchen, Horsfall, \& Armstrong, 2007). The critical agenda of this study aims at problematizing and questioning the taken-for granted policy of teaching the ME curriculum through the English language and the assumption that such a dogma has to be submitted to and perpetuated. To achieve this critical agenda, "we need to turn a skeptical eye toward assumptions, ideas that have become 'naturalized' notions that are no longer questioned" (Pennycook, 2001, p. 7). 


\section{Research Methodology}

Methodology is defined by Ernest (1994) as the theory in which methods and techniques are valid to be used to generate and rationalize knowledge in the light of the epistemology; it has also been explained by Someh and Lewen (2005) that methodology is the principles and methods upon which the research is built and is the frame of reference for the research which is influenced by the paradigm. The intended qualitative methodology, or the research strategy indicating a theory of obtaining knowledge (Troudi, 2010), for this study is seen to be the most feasible process that would probably reflect on the kind of mustered evidence and consequently the type of reality to be represented in the form of attempting the research questions. Qualitative data collection instruments, namely semi-structured interviews, are seen to be the most convenient tools to obtain information on the reasons and impact of adopting English as the medium of instruction in teaching ME.

\section{Participants and Sampling Procedures}

Data gathering contributes to enhanced knowledge of the issue under scrutiny; thus, informant selection is crucial to research. What these informants say or do is an important element of qualitative research. Participants in the current study are purposively chosen; purposive sampling is a non-probability, non-random technique that denotes a deliberate choice of participants for the qualities they possess where the researcher chooses the kind of information to be exposed, then finds people who can deliver such knowledge (Tongco, 2007). The key informants in this study are ten full-time, middle and high school, veteran English language teachers, in addition to three of the senior management team who all work for a private school in Dubai, UAE. They are chosen for being observant, reflective teachers and management representatives who are willing to share their perceptions and experiences about implementing EMI in teaching ME.

\section{Data Collection Methods}

A method refers to the particular technique or instrument used in the data collection process or the systematic procedures used for data collection and analysis (Mackenzie \& Knipe, 2006). Instrumentation or the pacing factor of research is believed to be the process of selecting and designing research instruments as well as considering the underlying conditions of administering those instruments. The tools a researcher utilizes in observing, measuring, and making sense of nature determine his/her productivity (Fraenkel, Wallen \& Hyun, 2012).

Two sets of semi-structured interviews were chosen as the data collection methods for the study in hand. Kvale (2008) defines a semi-structured interview as a purposeful everyday conversation that involves a certain technique. Creswell (2014) describes interviews as an approach to investigate the meaning assigned to a social dilemma. A semi-structured interview comprises a number of formerly formulated questions planned to be appropriately open and subsequent questions are to be improvised which is referred to by Drever (2003) as 'adaptability.' Delving into teachers' attitudes towards the imposed policy is essential to ensure that the teachers' voice is heard. In addition, the purpose of employing semi-structured interviews 
with the administrative personnel is to obtain a comprehensive insight into the perceptions of policy makers on the target policy. In this respect, building upon notions of the self-monitoring teacher and the teacher as extended professional and to place the teachers' classroom practices at the centre of action research is crucial for the intended reform.

\section{Procedures}

Individual, face-to-face, semi-structured interviews were conducted with all participants to help capture the problem and explore participants' attitudes (Creswell, 2014). Each interview lasted for about 40 minutes. Interviews were individually administered so that the researcher could steer the discussion in the desired direction and create an atmosphere of discretion that helped respondents discuss their personal views openly. Face-to-face interviews were considered more convenient in terms of observing the teachers' non-verbal responses, e.g. body language, tone, hesitation and facial expressions. Semi-structured interviews were beneficial for their adaptability and the comprehensive data they provide (Lodico, Spaulding, \& Voegtle, 2010). To help respondents better communicate their experiences and reflect on the questions, a nonthreatening environment was arranged. Qualitative audio recordings of the interviews were collected to ensure reliable analyses of transcribed data (Creswell, 2014).

\section{Ethical Considerations}

It is imperative for a researcher to take research ethics into consideration; putting in place safeguards to protect participants' rights is a principal issue in the context of educational research. A permission from the site gatekeeper, namely the school principal, as well as informed consent from partakers were obtained prior to data collection and analysis. Contributors to this research were advised of the research purposes and the voluntary nature of the study; data privacy was respected and secured through positive measures among which is using pseudonyms to conceal their identities (Burgess, 2005).

\section{Credibility and Transferability}

Qualitative validity, or the precision in which the findings accurately reflect the data, and reliability, or the consistency in analytical procedures and findings, are intrinsic in the authenticity of the collected data. Credibility refers to the truth-value of the research findings and whether these findings offer plausible information and correct interpretations drawn from the participants (Korstjens \& Moser, 2018). In this study, credibility is ensured through the prolonged engagement strategy where the researcher built up trust by introducing herself, discussing her research purposes, and ensuring confidentiality of information and tested misinformation through employing follow-up questions. The persistent observation of key elements through recording and labelling codes is another credibility-guarantee strategy. Conducting in-depth interviews and taking field notes are also followed as data triangulation strategies. Transferability or using thick descriptions of context, behaviour, and experience to 
enable the readers to decide if the findings are transferable to their own settings is also attempted in this study.

\section{Research Design}

All interviews were transcribed, color-coded, then manually analysed. As stated by McLellan, MacQueen and Neidig (2003), there is no one universal format for transcribing all types of qualitative data; it is stressed that producing transcripts is a research activity that should precede data analysis for a researcher to decide on what is to be included in the research. A thematic color-coding, manual analysis then took place based on discussed themes.

\section{Teachers' Perceptions}

\section{Instructional Language Preference}

While seven out of ten interviewees emphasized that they prefer ME curriculum to be taught in the students' L1, which is the Arabic language, the other three teachers made it clear that adopting English as the language of instruction is more advantageous for both parties, teachers and students. Among the justifications made against implementing EMI in teaching ME was what Salma said,

Teaching Morals in English was a really difficult experience. This is simply because I am teaching morals to students whose mother tongue is Arabic. The idea is that when using a foreign language to teach morals, students show less emotional reactions which contradicts to the goal of the curriculum.

Another reason that has to do with both teachers and students was mentioned by Nina, "the books contain some difficult terms which makes it harder for teachers to convey the information to the students." Hady proposed a considerable argument saying that,

Teaching ME in English has not always been enjoyable for me since most of the students don't take this subject seriously. I believe that the main focus of ME is to increase students' awareness about the world around them and delivering instructions using the students' first language will serve this goal better. This particular opinion is built on teachers' observations, in addition to students' opinions which are way more realistic than senior managements' vision.

Ashraf also propounded that not only students' second language forms an obstacle to their understanding but also the technical topics and terminology offered in the curriculum burden the teachers,

Teaching ME in English for Arab students is like an aimless challenge that added a burden on learners and expanded their language barriers too. Arab students can easily absorb the concepts of the curriculum if they are taught in Arabic and supported by relevant activities. Besides, ME concepts are sometimes pure economic topics that require business teachers to teach and support by a full-term project to implement the core idea in a practical way.

Muna held a similar opinion to Ashraf's,

Honestly speaking, being a ME teacher for 12 graders is very hard for me since the curriculum mainly discusses finance and corruption. I find it irrelevant to what I used to teach in 
the past years. Even preparing the lessons consumes double the time I use to prepare for English classes.

All seven teachers affirmed that they would choose Arabic as the medium of instruction in teaching ME if they were granted the opportunity to decide; the range of reasons mentioned by the teachers revolved around the cognitive accessibility of students to the taught ME concepts. As explained by Muna "teaching ME in Arabic would be better for both students and teachers." Murad added that, "I believe English-medium instruction policy in teaching ME is not the best policy to be followed. If the decision was mine, I would choose the mother tongue of the students to be the medium of instruction."

On the other hand, Mahmoud perceived the language of instruction differently; he believed that teaching ME in English distances it from other comparable subjects that feature morals in different contexts such as Islamic Studies. He added that it emphasizes on global values that should be demonstrated by everyone apart from their background, religion and culture. In addition, he asserted that "teaching $M E$ in the most dominant language help students develop into ethical and responsible human beings within worldwide concepts." Owen also expressed a similar preference saying that,

As a teacher in an American school, the choice would definitely be to teach ME in English simply because it concretizes the diversity of information exchanged with the learners and supports the curriculum's main learning aims.

\section{The Impact of EMI on Students' Performance and Learning Outcomes}

As for the teachers' impression on the impact of using English as the instructional language of ME, the participant teachers held diversified stances. Hady has made his position clear arguing that,

Integrating Arabic language every once in a while, during class discussions had a great impact on students' concentration and productivity. I have noticed that a considerable number of students started participating more whenever the instructions and topics were presented in Arabic.

Similarly, Murad contended that teaching ME in English has had only negative effects on students,

At both the behavioural and affective levels, a good portion of students are not effectively engaged as they are being isolated by their cognitive ability to decode a language that is not their mother tongue. This negative impact is evident on students' achievement and on the overall curriculum outcomes.

The affective dimension of teaching ME in a foreign language was also referred to by Amr, Since Arabic is deeply implanted in the Emirati culture, English barely touches their emotions and feelings; I don't find English as the suitable language to teach this moral subject. I can compare that to teaching Islamic Studies in English; you will find that students do not side with discussed topics or digest them. 
The negative impact of teaching ME was maintained by other teachers for an array of other reasons than the medium of instruction. Ashraf, for example, claimed that "as a matter of fact, morals and ethics are not issues to be taught. They are more likely to be practiced." In his opinion, "to eliminate students' passive attitudes, everyone can set an example of a moral behaviour in his/her own style rather than teaching theories and announcing statements." Nina explained that students' attitudes towards ME curriculum have to do with the content; she asserted that her students showed interest towards topics that were related to real life issues but would act disruptively if the proposed topic was irrelevant to their areas of interest. Despite being an advocate of EMI in teaching ME, Warda stipulated that she would choose to remain a teacher of English only even if it had to be at the expense of teaching ME curriculum at all.

Muna had also presented a different line of reasoning against teaching ME curriculum, $M E$ with its current content adds nothing to my students. When first informed that there is a new book, I was the first to support the idea but was shocked to discover that the content has nothing to do with what my students and I have expected. Only those interested in accounting and finance liked the lessons, other students were not even triggered to participate.

Mahmoud and Owen, on the contrary, mentioned some positive effects of EMI amongst which are what Mahmoud highlighted,

Students will sometimes correlate ME with other subjects taught in English like English and Global Issues specially that some of the morals and themes reoccur in a number of literature selections and global trends as well. It also helps to enrich their vocabulary and word choice skills.

Owenaverred that teaching ME curriculum in English enhanced students' linguistic abilities and enriched their knowledge; he stated that,

The English-medium of instruction is a key to students to have a closer look on some other topics that might not be touched on in the curriculum...it is complementary since it corrects their behaviour and compares them to oriental societies and civilized behaviours.

\section{Teachers' Voice and Decision-making}

Regardless of being a proponent or an opponent of the seemingly imposed policy, all teachers confirmed that their voice was never heard by the senior management personnel. Owen reflected his contempt for the administrative approach of making all decisions without involving the teachers,

Our voice is not really taken into account whenever it comes to deciding on such an important detail though it should be. Teachers' voice is crucial to curriculum related decisions. Teacher's vision I find more reliable since they are in contact with students and aware of their educational and behavioural problems.

Warda emphasized the same opinion saying that "I think making decisions is a far fetching goal for teachers." She went on to say that "the administration is always having the upper hand. In some rare circumstances, decisions are ours and mostly limited to the classroom." Nina added that "admins never run surveys or discuss the choice of ME books with teachers." Salma 
described teachers as being entitled to obtain realistic feedback from their students on a daily basis and thus eligible to make such decisions. Anas thought that his viewpoint is more practical and efficient "if school admin people really want to achieve their claimed goal of creating a student-centred learning environment."

While Hady believed that teachers and students are the two main stakeholders and their opinions should be prioritized over the management's, Murad thought that "everyone's voice should be heard. The issue is to what extent the decision will be taken accordingly." $\mathrm{He}$ proceeded by drawing an analogy where he compared teachers to warriors and teachers' vision to "authentic snapshots from the actual battlefield." Muna clarified that teachers had never been asked to make a decision as "they are not supported or taken seriously by the admins although teachers know what works and what doesn't work for their students." An additional valid point was disputed by Ashraf,

My voice is not heard neither as a teacher nor as the English coordinator of the high school. The decision is taken merely by the school administration without any consultation from my side. Even when I tried to talk about this issue, my voice was completely ignored. I believe that teachers' visions are of vital importance as the key players in the implementation process.

Mahmoud corroborated that "teachers can see the merits and demerits of using one method or the other inside the classroom. Besides, students should have a say in what they learn."

\section{Administrators' Perceptions}

Tackling the issue from the management viewpoint, more and different themes have evolved. The first senior management personnel(SM1) explained that as an American school, there are restrictions on using any language other than English and the use of Arabic should not extend beyond Arabic language and Islamic Studies classes. He emphasized the fact that NEASC (New England Association of Schools and Colleges) and KHDA (Knowledge and Human Development Authority) would only expect them to be strict in implementing such a policy. Otherwise, the evaluation processes administered by the early mentioned parties might be greatly affected. When asked about the English teachers' compressed schedules, SM1 answered saying that, "teaching morals should be every teacher's responsibility and English language teachers are no exception." He added that teaching ME in English "is basically teaching English and that teachers should make use of such an opportunity." He also suggested that ME could be taught in Arabic for grades K-5 as the students' English language competency is underdeveloped, while maintain teaching ME in English to grades 6-12.

The second senior management personnel (SM2) questioned the teachers' intention behind their rejection of the policy of teaching ME through English when he said, "frankly, there is a lack of trust between teachers who might have personal agendas, and the school board members who are able to see the whole picture." He attributed the fact that teachers' voice is completely disregarded to the mistrust between the two parties. He insisted that "neither the school management nor the teachers should yield to the students' demands as they tend to take the easiest path. The only solution is to raise the bar and expect more from our students." 
The third senior management personnel (SM3) argued that "English is seen to be the only common ground for communication between Arab and non-Arab students." According to her viewpoint, "all students should be able to fluently represent themselves in English as per the National Agenda parameters that emphasize the development of a first-rate educational system across the country." She pointed out that through maintaining high educational standards, part of which is implementing the policy of EMI in teaching all subjects except for Arabic and Islamic studies, students would be more prepared for the international job market. Another point raised by the SM3was the claim that "Islamic Studies subject already teaches the same concepts in Arabic, so why not to offer the English equivalent to our students." As for the teachers' schedules, her justification was that "English teachers can take advantage of ME classes to train students on debating and other speaking skills related to the English language but topic-related to ME curriculum.”

\section{Conclusion}

All three research questions are thoroughly addressed through the administered sets of interviews. First, it can be strongly claimed that the policy of adopting EMI in teaching ME is imposed on both teachers and students. It has also become evident that teachers' voice is completely unheeded and that all decisions are merely made by the senior management. In addition, the words 'mistrust' and 'personal agendas' have brought the concepts of transparency and professionalism into question; using these two words that obviously have negative connotations by a school management personnel should give an indication of the kind of workplace this is. This study result is in line with what Bas and Sentürk (2019)mention about the minor and uncertain role teachers assume in the decision-making process specially that related to curriculum development. According to BAS and TABANCALI (2020), teachers' voice is one way for a school "to create a culture of innovation and a prerequisite for improvement of school" (p. 195) and that rewarding teachers' voice would draw any organization closer to achieving their goals. Secondly, the majority of the interviewed teachers show preference for teaching ME through Arabic as the students' first language rather than through their second language which happens to be English. This result resonates with Cankaya's (2017) study results which indicate that students' level of understanding of the subject matter due to language-related problems is substantially low. In addition, Costa et al. (2014) explains that the cognitive load of using a language other than the mother tongue decreases the "utilitarian choice in moral dilemmas" (p.1).

Moreover, the incongruity between the senior management's vision of persistence in implementing the EMI policy in teaching ME across all grade levels and the SM1's suggestion of teaching $\mathrm{ME}$ in Arabic for some grades reflects the inconsistency and unreliability of the school vision in relation to the target policy. Another point that is worth highlighting is the discrepancy between what the teachers stated and what SM3professes about the content of the ME curriculum; while some teachers asserted that the content of ME for some grade levels is more related to business and accounting, SM3purports that ME curriculum aligns with Islamic 
Studies curriculum and thus there is no need to teach both in Arabic! In conclusion, the study results are quite consonant with what Simkins (2005) mentions about how we now live in a world dominated by the notion that leadership is one- if not the only one- of the key factors that decide whether an educational organization will succeed or fail. In the education policy discourse, policy makers are described as "elite network-actors from government, business, entrepreneurial philanthropy, think tanks, and policy institutes inhabiting a position of relative advantage"compared to the'non-elite policy actors'including teachers and students who struggle to produce and actualize the imposed educational policy (Ellison et al., 2018, p.158). Even though we think we know so much, leadership in education remains a stubbornly difficult activity.

\section{Implications}

The implications mentioned here are basically suggestions made by some of the interviewed teachers; Amr suggested that in order to prove whose vision is correct, a comparison between the effect of teaching ME in Arabic and the outcome of teaching it in English should take place. Another was presented by Hady who recommended a revision of ME curriculum to make the content more real-life related. A third recommendation would be adopting a contextual approach to teaching ME; a whole-school curriculum should be planned to link teaching and other educational activities in a more systematic way.

\section{Limitations}

Among the limitations of the study is the number of participants; interviewing teachers from other English and Arabic schools could have brought more themes to the spotlight. Another limitation is data triangulation or the strategy used by researchers to improve the validity and reliability of research findings; reliability or consistency of data results is achievable when the data collection method produces the same results about the observed phenomenon regardless of who makes the observations (Golafshani, 2003). In the light of the adopted paradigm in my study, the reliability and trustworthiness of the research findings could have been increased upon employing an additional data collection method.

\section{References}

Adil, M. (2019). Practical application of learners' first language to Teaching meaning in EFL classes: A case study conducted in the department of English at King Khalid University. Arab World English Journal, Special Issue: The Dynamics of EFL in Saudi Arabia, 170-187.

Alamri, B. (2019). Foreign Culture in English Curriculum in Saudi Arabia: A Teacher's Voice. Arab World English Journal, Special Issue 1: Application of Global ELT Practices in Saudi Arabia, 34- 41. DOI: https://dx.doi.org/10.24093/awej/elt1.3

Alenezi, A.A. (2010). Students' language attitude towards using code-switching as a medium of instruction in the college of health sciences: An exploratory study. ARECLS, 7, 1-22.

Alhamami, M. (2015). Teaching science subjects in Arabic: Arab university scientists' perspectives. Language Learning in Higher Education, 5 (1), 105-123. 
Al-Issa, A. (2017). English as a medium of instruction and the endangerment of Arabic literacy: The case of the United Arab Emirates. Arab World English Journal, 8 (2), 3-17.

Almoayidi, K. A. (2018). The effectiveness of using L1 in second language classrooms: A controversial issue. Theory and Practice in Language Studies, 8(4), 375-379.

Aloni, N. (2020). Locally grounded, universally binding: The benefit of incorporating traditional care ethics, East and West, into current moral education. Educational Philosophy and Theory, 52(1), 98-105.

Bas, G., \& Sentürk, C. (2019). Teachers' voice: Teacher participation in curriculum development process. ie: Inquiry in Education, 11(1), 1-31.

BAS, S., \& TABANCALI, E. (2020). Correlations between teachers' personality, psychological safety perception and teacher voice. Eurasian Journal of Educational Research (EJER), 85, 185-204.

Bayer, T. I. (2017). Moral philosophy and moral education. Wipf and Stock Publishers. Retrieved from https://ebookcentral.proquest.com

Belhiah, H., \& Elhami, M. (2015). English as a medium of instruction in the Gulf: When students and teachers speak. Language Policy, 14(1), 3-23.

Berkowitz, M. W., \& Bier, M. C. (2004). Based character education. The Annals of the American Academy of Political and Social Science, 591(1), 72-85.

Bleazby, J. (2020). Fostering moral understanding, moral inquiry \& moral habits through philosophy in schools: ADeweyian analysis of Australia's Ethical Understanding curriculum. Journal of Curriculum Studies, 52(1), 84100.

Butzkamm, W. (2003). We only learn language once. The role of the mother tongue in FL classrooms: death of a dogma. Language Learning Journal, 28(1), 29-39.

Burgess, R. G. (Ed.). (2005). The ethics of educational research. UK: The Falmer Press.

Cankaya, P. (2017). Challenges in English Medium of Instruction from the Teachers and Students' Eyes. International Journal of Languages' Education and Teaching, 5(4), 830-839.

Costa, A., Foucart, A., Hayakawa, S., Aparici, M., Apesteguia, J., Heafner, J., \&Keysar, B. (2014). Your morals depend on language. PIOS ONE, 9(4), 1-7.

Creswell, J.W. (2014). Research design: Qualitative, quantitative, and mixed methods approaches. (4 ${ }^{\text {th }}$ ed.). Thousand Oaks: SAGE Publications.

Demirel, M., Özmat, D., \& Elgün, I. Ö. (2016). Primary school teachers' perceptions about character education. Educational Research and Reviews, 11(17), 1622-1633

Drever, E. (2003). Using semi-structured interviews in small-scale research: A teacher's guide. Glasgow: SCRE Centre, University of Glasgow.

Dujmović, M. (2014). The ways of using mother tongue in English language teaching. International Journal of Language and Linguistics, 2(1), 38-43.

Durmuş, Y. T. (2019). Early childhood education teachers' experiences on moral dilemmas and suggestions for morality and ethics in education course in faculty of educations. International Journal of Progressive Education, 15(5), 301-314.

Ellison, S., Anderson, A. B., Aronson, B., \& Clausen, C. (2018). From objects to subjects: Repositioning teachers as policy actors doing policy work. Teaching and Teacher Education, 74, 157-169.

Ernest, P. (1994). An introduction to research methodology and paradigms. Exeter: University of Exeter.

Fraenkel, J.R., Wallen, N.E., Hyun, H. (2012). How to design and evaluate research in education (8 $8^{\text {th }}$ ed.). New York: McGraw-Hill Humanities/Social Sciences/Languages.

Garrod, A. C., \& Bramble, G. A. (1977). Moral development and literature. Theory into Practice, 16(2), $105-111$. 
Golafshani, N. (2003). Understanding reliability and validity in qualitative research. The Qualitative Report, 8(4), 597-607.

Hall, R. T. (1979). Moral education: A handbook for teachers. Insights and practical strategies for helping adolescents to become more caring, thoughtful, and responsible persons. Minneapolis, USA: Winston Press, Inc.

Higgs, J., Titchen, A., Horsfall, D., \& Armstrong, H. (2007). Researching practice: A discourse on qualitative methodologies. Denver, U.S.: Hampden Press.

KHDA supplement (n.d.). Retrieved fromhttps://www.khda.gov.ae/Areas/Administration/Content/FileUploads/Publication/Documents/English/20170 71615123020170716144744 School_Inspection_Supplement_En.pdf

Korstjens, I., \& Moser, A. (2018). Series: Practical guidance to qualitative research. Part 4: Trustworthiness and publishing. European Journal of General Practice, 24, 120-124.

Krek, J., Hodnik, T., \&Vogrinc, J. (2019). The primary school moral education plan in Slovenia ten years after its introduction. European Journal of Educational Research, 8(4), 1229-1243.

Kvale, S. (2008). Doing interviews. Thousand Oaks, CA: Sage Publications Inc.

Lewis, C. J. (2019). Vygotsky and moral education: A response to and expansion of Tappan. Educational Philosophy and Theory, 51(1), 41-50.

Levine, G. S. (2014). Principles for code choice in the foreign language classroom: A focus on grammaring. Language Teaching, 47 (3), 332-348.

Lodico, M., Spaulding, D., \& Voegtle, K. (2010). Methods in educational research. (2 ${ }^{\text {nd }}$ ed.). San Francisco: John Wiley\& Sons.

Macaro, E. (2018). English medium instruction. UK: Oxford University Press.

Mackenzie, N., \& Knipe, S. (2006). Research dilemmas: Paradigms, methods and methodology. Issues in Educational Research, 16(2), 193-205.

McLellan, E., MacQueen, K. M., \& Neidig, J. L. (2003). Beyond the qualitative interview: Data preparation and transcription. Field Methods, 15(1), 63-84.

Meindl, P., Quirk, A., \& Graham, J. (2018). Best practices for school-based moral education. Policy Insights from the Behavioral and Brain Sciences, 5(1), 3-10.

Moore-Jones, P. J. (2015). Linguistic imposition: The policies and perils of English as a medium of instruction in the United Arab Emirates. Journal of ELT and Applied Linguistics (JELTAL), 3(1), pp. 63-73.

Nishino, M. (2017). The challenge of developing meaningful curriculum initiatives for moral education in Japan. Journal of Moral Education, 46(1), 46-57.

Pennycook, A. (2001). Critical applied linguistics: A critical introduction. New Jersey, U.S.: Lawrence Erlbaum Associates, Inc.

Pring, R. (2019) Development of moral education in the UAE: Lessons to be learned. Oxford Review of Education, 45(3), 297-314.

Qin, X. (2018). Design and Application of College Students' Moral Education Management System. Paper presented at the International Conference on Intelligent Transportation, Big Data \& Smart City (ICITBS), Xiamen. Retrieved from https://scholar.google.com/scholar?hl=en\&as_sdt=0\%2C5\&q=Design+and+Application+of + College + Students $\%$ 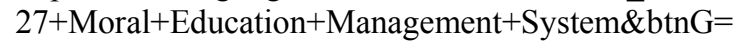

Shaaban, K. (2005). A proposed framework for incorporating moral education into the ESL/EFL classroom. Language, Culture and Curriculum, 18(2), 201-217.

Simkins, T. (2005). Leadership in education: 'What works' or 'what makes sense'?. Educational Management Administration \& Leadership, 33(1), 9-26. 
Tantawy, N. (2020). Investigating Teachers' Perceptions of the Influence of Professional Development on Teachers' Performance and Career Progression. Arab World English Journal, 11(1) 181-194.

Tongco, M. D. C. (2007). Purposive sampling as a tool for informant selection. Ethnobotany Research and Applications, 5, 147-158.

Troudi, S. (2009). The effects of English as a medium of instruction on Arabic as a language of science and academia. In P. Wachob (Ed.). Power in the EFL classroom: Critical pedagogy in the Middle East (pp. 199216). Cambridge Scholars Publishing.

Troudi, S. (2010). Paradigmatic nature and theoretical framework in educational research. In M. Al-Hamly et al (Eds.), English in learning: Learning in English (pp. 315-323). Dubai: TESOL Arabia Publications.

UAE policy (n.d.).Retrieved from https://www.tellalinstitute.com/tellal-talks/moral-education-in-the-uae/

van der Kooij, J. C., de Ruyter, D. J., \& Miedema, S. (2015). The influence of moral education on the personal worldview of students. Journal of Moral Education, 44(3), 346-363.

Wanphet, P., \& Tantawy, N. (2018). Effectiveness of the policy of English as a medium of instruction: Perspectives and outcomes from the instructors and students of university science courses at a university in the UAE. Educational Research for Policy and Practice, 17(2), 145-172.

Was, C. A., Woltz, D. J., \& Drew, C. (2006). Evaluating character education programs and missing the target: A critique of existing research. Educational Research Review, 1(2), 148-156.

Watson, B. (2018). Religious education and moral education. In P. Barnes (Ed.). Learning to teach religious education in the secondary school: A companion to school experience (pp.164-181). New York: Routledge.

Wilkinson, A., Gollan, P. J., Kalfa, S., \& Xu, Y. (2018). Voices unheard: Employee voice in the new century. International Journal of Human Resource Management, 29(5), 711-724. 